\title{
Emission from small scale PV-installations on the low voltage grid
}

\author{
S. Rönnberg ${ }^{1}$, M. Bollen ${ }^{1}$ and A. Larsson ${ }^{1}$ \\ ${ }^{1}$ Electric Power Engineering Group \\ Luleå University of Technology \\ Skellefteå Sweden \\ Phone:+46910585721, e-mail: sarah.ronnberg@ltu.se, math.bollen@ltu.se
}

\begin{abstract}
The use of solar panels is becoming more popular in Sweden. Parts of Scandinavia have many sun hours and the cold temperatures are advantageous as they lead to higher efficiencies and longer lifetimes of the solar cells. In this paper conducted emission levels associated with the connection of photovoltaic systems will be discussed. Harmonics (up to $2 \mathrm{kHz}$ ) and supraharmonics (2 to 150 $\mathrm{kHz})$ will be discussed. Measurements from three phase connected plants (20 kW) and from smaller (up to $2.5 \mathrm{~kW}$ ) single phase connected plants are shown.

The harmonic emission from PV-plants is reasonably low and somewhat constant with regards to the production. Some residue from the switching of the inverter can be found typical at a few $\mathrm{kHz}$.
\end{abstract}

\section{Introduction}

The PV-inverter injects current on the power grid that is to some extent distorted. This could lead to high levels of voltage distortions if the grid impedance is high, as could especially be the case because of resonances.

The potential consequences of high voltage and current distortion are discussed in various textbooks [1-3]. Waveform distortion is however well regulated in most countries, through compulsory or voluntary limits. A specific issue with harmonic emission from production units connected to the distribution network is that such units typically do not require strengthening of the grid. When adding more consumer equipment to the distribution grid, this requires bigger transformers and cables or lines, with lower source impedance as a result. With the connection of distributed generation, the amount of equipment connected to the grid can grow, without any reduction in source impedance.

Harmonic studies have traditionally been limited to frequencies up to about $2 \mathrm{kHz}$, with the main concern being the low-order odd harmonics. More recently, the frequency range above $2 \mathrm{kHz}$ has received attention, especially in standardization but also in research [4-7]. The frequency range 2 to $150 \mathrm{kHz}$ is referred to as "supraharmonics" This term was introduced during the 2013 IEEE PES General meeting [8]. Almost no limits exist on this frequency range in standards, but this does not require that this range can be neglected. To the opposite, the lack of standards requires a serious mapping of the emission, propagation and other aspects so as to form a basis for the standardization work that is ongoing in this frequency range.

This paper presents measurements from a number of PVinstallations in Scandinavia with focus on emission up to $150 \mathrm{kHz}$.

\section{Measurement Results}

Continuous measurements have been performed at several different locations with PV installations of various sizes. Some of the results are presented in the forthcoming sections.

$\checkmark 20 \mathrm{~kW}$ installation in Skellefteå, Sweden. (Referred to as Sweden 1) Three phase connection.

$\checkmark 20 \mathrm{~kW}$ installation in Piteå, Sweden. (Referred to as Sweden 2) Three phase connection.

$\checkmark \quad 1.5 \mathrm{~kW}$ installation in Narvik, Norway. Single phase connection.

$\checkmark \quad 2 \mathrm{~kW}$ installation in Loue, Finland. Single phase connection.

$\checkmark \quad 2.5 \mathrm{~kW}$ installation in Skellefteå, Sweden. Single phase connection, mounted at the roof of the Pehr Högström laboratory at Luleå University of Technology in Skellefteå 


\section{Harmonic Emission}

At high production the PV installations are near unity power factor and the current harmonic emission expressed as percent of fundamental is relatively low. At high production the fundamental waveform dominates and the emission is relatively low. In Figure 1 the current and voltage waveform from a $2 \mathrm{~kW}$ installation are shown for high and low production. As can be seen in the figure, the current waveform is close to sinusoidal, especially at high production, even if there are some deviations.
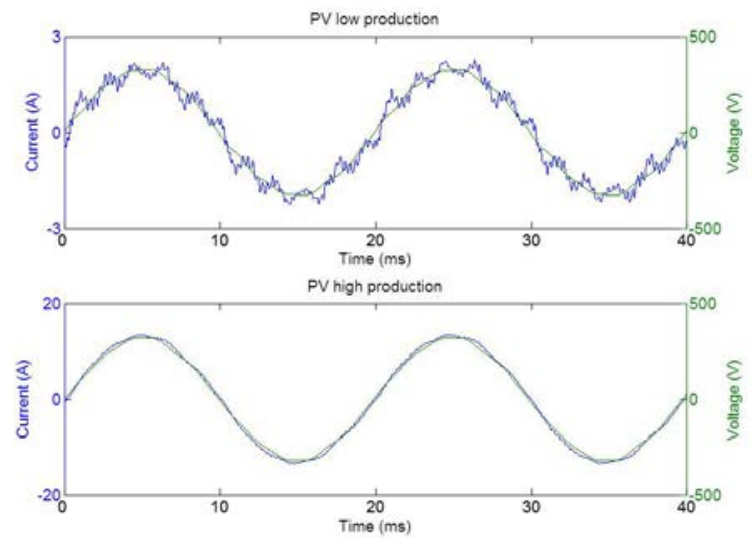

Figure 1 Voltage (green) and current (blue) waveform from a $2 \mathrm{~kW}$ installation in Finland at low (top) and high (bottom) production levels. Note the difference in vertical scale.

The total current harmonic emission from the PV-plants varies over time, it is always present during production but the amplitude is not positively correlated to the amount of production as can be seen in Figure 2 where a measurement from one phase at one of the $20 \mathrm{~kW}$ plants during three days is shown. The distortion is given in Ampere, not in percent of fundamental or in percent of rated. The vertical scale $(0.8 \mathrm{~A})$ corresponds to $2.7 \%$ of rated current.

At zero production the total harmonic current amplitude is also close to zero. At medium and high production the variation in amplitude of the total harmonic current is small. The highest values are found at low levels of production as seen in Figure 2.

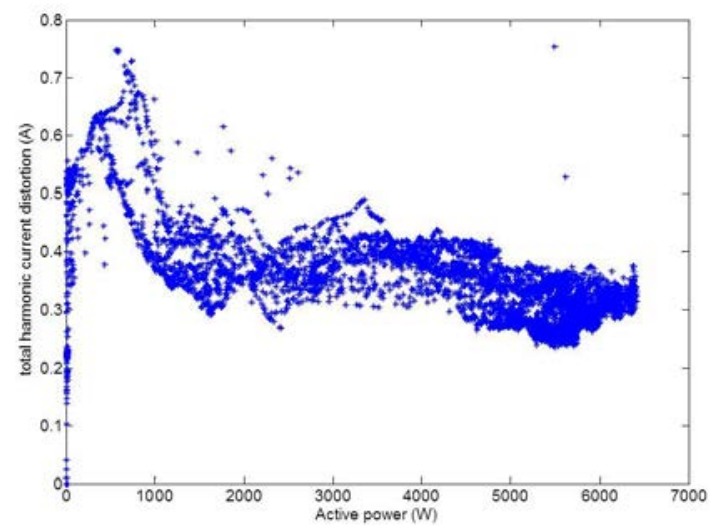

Figure 2 Current distortion for different production levels
In Figure 3 the harmonic spectrum during full production from four different PV installations is shown. The four different spectra show some dissimilarity but the dominating harmonics found are the same as those traditionally associated with non-linear loads at the low voltage grid, i.e. the lower order odd harmonics.
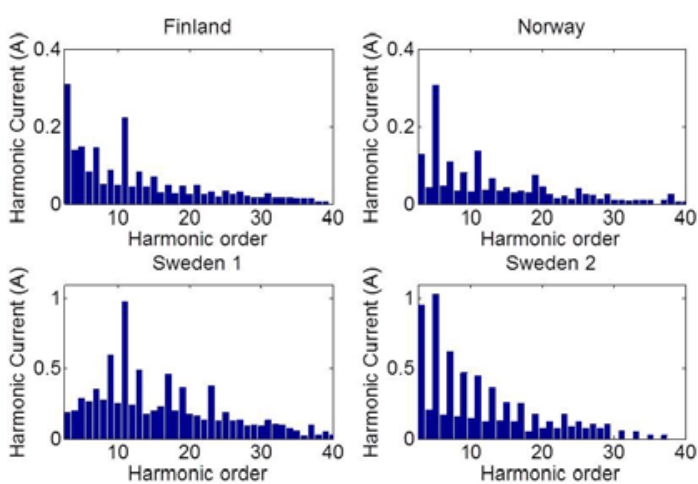

Figure 3 Spectra of the max amplitude during full production at four different locations

It is shown that the individual harmonic magnitude is not directly linked to the production level in the sense that the highest harmonic amplitude is not found at the highest fundamental $(50 \mathrm{~Hz})$ amplitude in all cases. For the third harmonic current it can be seen in Figure 4 that at the location in Finland the magnitude seems to increase with increased power. This is not the case at the three other locations where the highest magnitudes occur for low production, then decrease and somewhat level out for higher production.
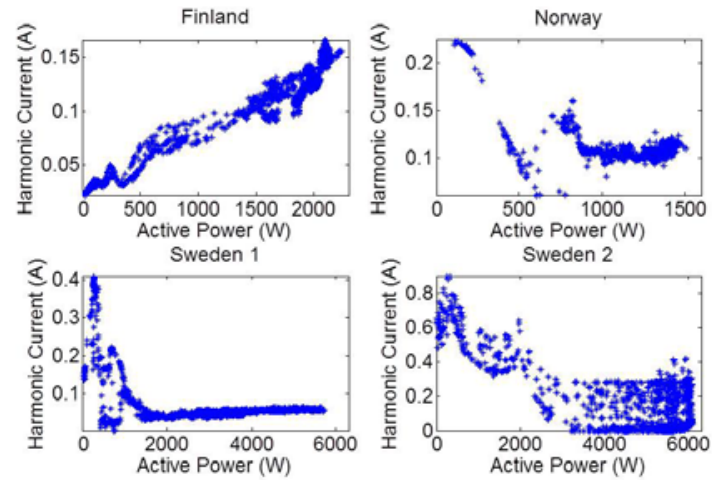

Figure 4 Average magnitude of the 3rd harmonic at four different locations during different production levels

As the production levels for PV fluctuate, the production was divided into four levels:

$\checkmark$ Low, corresponds to production up to $30 \%$ of peak production

$\checkmark$ Low to medium, corresponds to production from $30 \%$ to $50 \%$ of peak production

$\checkmark$ Medium to high, corresponds to production from $50 \%$ to $70 \%$ of peak production

$\checkmark$ High, corresponds to production up from $70 \%$ to $100 \%$ of peak production

The 95\% value of the max amplitude for odd harmonics 3 to 11 is shown in Table 1 to Table 4 for the different production levels at four locations. 
Table $195 \%$ value of the harmonic amplitude during different levels of production at location Sweden 1

\begin{tabular}{|l|l|l|l|l|l|l|}
\hline $\begin{array}{l}\text { Production } \\
\text { level } \\
\text { (Sweden 1) }\end{array}$ & $\begin{array}{l}\text { Active } \\
\text { power } \\
\text { (W) }\end{array}$ & $\begin{array}{l}\text { H3 } \\
\text { (A) }\end{array}$ & $\begin{array}{l}\text { H5 } \\
\text { (A) }\end{array}$ & $\begin{array}{l}\text { H7 } \\
\text { (A) }\end{array}$ & $\begin{array}{l}\text { H9 } \\
\text { (A) }\end{array}$ & $\begin{array}{l}\text { H11 } \\
\text { (A) }\end{array}$ \\
\hline Low & 1901 & 0,956 & 0,796 & 0,569 & 0,703 & 0,454 \\
\hline $\begin{array}{l}\text { Low to } \\
\text { medium }\end{array}$ & 3328 & 0,178 & 0,284 & 0,308 & 0,765 & 0,506 \\
\hline $\begin{array}{l}\text { Medium to } \\
\text { high }\end{array}$ & 4676 & 0,235 & 0,381 & 0,382 & 0,604 & 0,448 \\
\hline High & 5561 & 0,297 & 0,528 & 0,491 & 0,598 & 0,540 \\
\hline
\end{tabular}

Table 2 95\% value of the harmonic amplitude during different levels of production at location Sweden 2

\begin{tabular}{|l|l|l|l|l|l|l|}
\hline $\begin{array}{l}\text { Production } \\
\text { level } \\
\text { (Sweden 2) }\end{array}$ & $\begin{array}{l}\text { Active } \\
\text { power } \\
\text { (W) }\end{array}$ & H3 (A) & $\begin{array}{l}\text { H5 } \\
\text { (A) }\end{array}$ & $\begin{array}{l}\text { H7 } \\
\text { (A) }\end{array}$ & $\begin{array}{l}\text { H9 } \\
\text { (A) }\end{array}$ & $\begin{array}{l}\text { H11 } \\
\text { (A) }\end{array}$ \\
\hline Low & 1802 & 0,580 & 0,328 & 0,342 & 0,109 & 0,098 \\
\hline $\begin{array}{l}\text { Low to } \\
\text { medium }\end{array}$ & 3269 & 0,138 & 0,244 & 0,426 & 0,109 & 0,101 \\
\hline $\begin{array}{l}\text { Medium to } \\
\text { high }\end{array}$ & 4626 & 0,124 & 0,251 & 0,400 & 0,049 & 0,077 \\
\hline High & 5759 & 0,131 & 0,242 & 0,210 & 0,035 & 0,035 \\
\hline
\end{tabular}

Table 3 95\% value of the harmonic amplitude during different levels of production at location Norway

\begin{tabular}{|l|l|l|l|l|l|l|}
\hline $\begin{array}{l}\text { Production } \\
\text { level } \\
\text { (Norway) }\end{array}$ & $\begin{array}{l}\text { Active } \\
\text { power } \\
\text { (W) }\end{array}$ & $\begin{array}{l}\text { H3 } \\
\text { (A) }\end{array}$ & $\begin{array}{l}\text { H5 } \\
\text { (A) }\end{array}$ & H7 (A) & $\begin{array}{l}\text { H9 } \\
\text { (A) }\end{array}$ & $\begin{array}{l}\text { H11 } \\
\text { (A) }\end{array}$ \\
\hline Low & 442 & 0,225 & 0,097 & 0,060 & 0,077 & 0,059 \\
\hline $\begin{array}{l}\text { Low to } \\
\text { medium }\end{array}$ & 747 & 0,167 & 0,149 & 0,153 & 0,095 & 0,107 \\
\hline $\begin{array}{l}\text { Medium to } \\
\text { high }\end{array}$ & 1044 & 0,148 & 0,198 & 0,114 & 0,101 & 0,082 \\
\hline High & 1249 & 0,119 & 0,202 & 0,066 & 0,064 & 0,118 \\
\hline
\end{tabular}

Table 4 95\% value of the harmonic amplitude during different levels of production at location Finland

\begin{tabular}{|l|l|l|l|l|l|l|}
\hline $\begin{array}{l}\text { Production } \\
\text { level } \\
\text { (Finland) }\end{array}$ & $\begin{array}{l}\text { Active } \\
\text { power } \\
\text { (W) }\end{array}$ & $\begin{array}{l}\text { H3 } \\
\text { (A) }\end{array}$ & $\begin{array}{l}\text { H5 } \\
\text { (A) }\end{array}$ & $\begin{array}{l}\text { H7 } \\
\text { (A) }\end{array}$ & $\begin{array}{l}\text { H9 } \\
\text { (A) }\end{array}$ & $\begin{array}{l}\text { H11 } \\
\text { (A) }\end{array}$ \\
\hline Low & 576 & 0,094 & 0,059 & 0,071 & 0,044 & 0,094 \\
\hline $\begin{array}{l}\text { Low to } \\
\text { medium }\end{array}$ & 989 & 0,118 & 0,077 & 0,096 & 0,049 & 0,122 \\
\hline $\begin{array}{l}\text { Medium to } \\
\text { high }\end{array}$ & 1391 & 0,146 & 0,088 & 0,102 & 0,062 & 0,126 \\
\hline High & 1715 & 0,178 & 0,112 & 0,126 & 0,059 & 0,142 \\
\hline
\end{tabular}

The emission at these frequencies is low, in terms of rated current the highest value (for any harmonic or range of production) is, for the four production units:

$\checkmark \quad$ Sweden 1 ; $3.3 \%$ of rated current ( $3^{\text {rd }}$ harmonic, low production)

$\checkmark$ Sweden 2; $2 \%$, of rated current ( $3^{\text {rd }}$ harmonic, low production)

$\checkmark$ Norway; $3.5 \%$, of rated current ( $3^{\text {rd }}$ harmonic, low production)

$\checkmark \quad$ Finland; $2 \%$, of rated current $\left(3^{\text {rd }}\right.$ harmonic, high production)

European standard IEC 61000-3-12 sets limit to harmonic currents produced by equipment connected to the low voltage grid with input current between $16 \mathrm{~A}$ and $75 \mathrm{~A}$. Measurements from the installation called Sweden 2 have been compared to the limits set by the aforementioned standard for individual harmonics. The strictest limits have been used; short-circuit ratio of 33 and a rated current of 30 A corresponding to the max current for a $20 \mathrm{~kW}$ production. Shown in Figure 4 is the individual harmonic current H3 to H9. The horizontal line corresponds to the limit set by IEC 61000-3-12. As can be seen in Figure 4 the magnitudes for odd harmonics 3 to 9 are well below the limits. This holds also for the other locations measured.
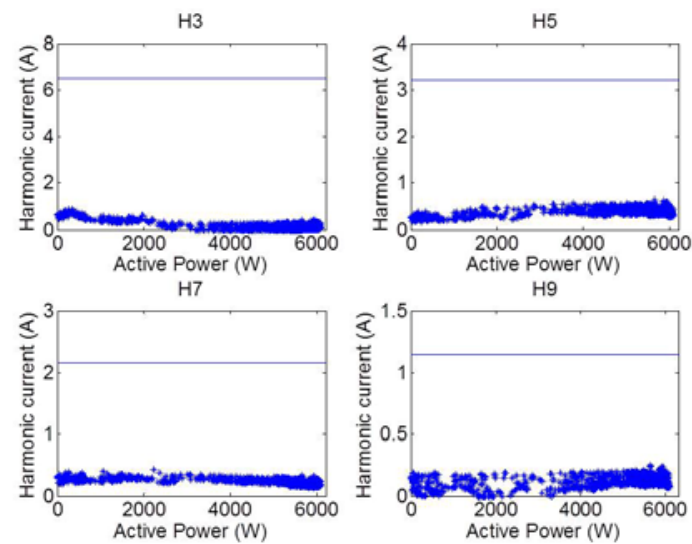

Figure 5 Individual harmonic current H3 to H9. Horizontal line corresponds to the limit set by IEC 61000-3-12

The only individual current harmonic found to exceed the limit set in IEC 61000-3-12 during the time frame of the measurements is harmonic 11 measured at the city town hall in Skellefteå (Sweden 1). The 6-min average of the eleventh harmonic was plotted in Figure 6 for the timeframe October 2012 until end of April 2013. The low levels in the middle of the measurement correspond to the wintertime when the PV-plant is not producing any electricity due to lack of irradiation and snow covering the panels.

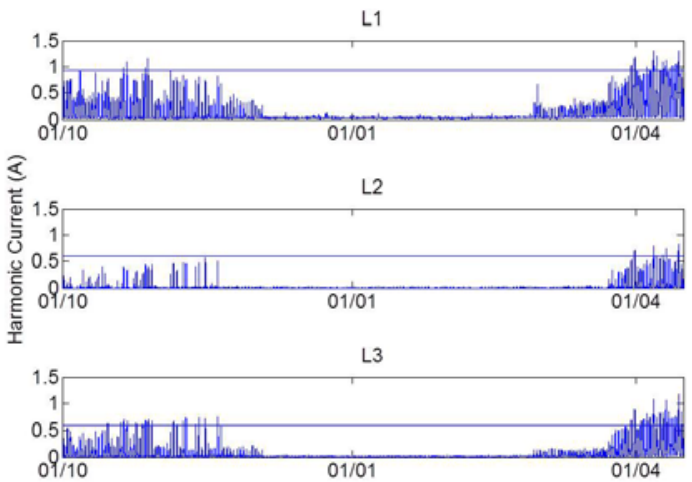

Figure 6 6-min average of the 11th harmonic over time at Sweden 1 . The horizontal line correspond to the limit set by IEC 61000-3-12

In Table 5 the correlation between active power and the amplitude of the individual odd harmonics 3 to 17 are shown. The overall strongest correlation is found for the $3^{\text {rd }}$ current harmonic at the location in Finland where the correlation is as high as 0.97 . However, there is no clear trend for individual current harmonics, some show negative correlation while others positive. Compering the same harmonic number for different location it is also shown that there is no clear trend; the $3^{\text {rd }}$ harmonic that showed strong positive correlation at the location in Finland has negative correlation at the other locations. 
Table 5 Linear correlation between active power and individual current harmonics

\begin{tabular}{|c|c|c|c|c|}
\hline $\begin{array}{l}\text { Harmonic } \\
\text { number }\end{array}$ & \multicolumn{1}{l|}{$\begin{array}{l}\text { Sweden } \\
\mathbf{1}\end{array}$} & $\begin{array}{l}\text { Sweden } \\
\mathbf{2}\end{array}$ & Norway & Finland \\
\hline $\mathbf{3}$ & $-0,51$ & $-0,75$ & $-0,5$ & 0,97 \\
\hline $\mathbf{5}$ & $-0,48$ & 0,42 & 0,48 & 0,91 \\
\hline $\mathbf{7}$ & 0,34 & $-0,57$ & $-0,16$ & 0,74 \\
\hline $\mathbf{9}$ & 0,36 & 0,33 & $-0,58$ & 0,74 \\
\hline $\mathbf{1 1}$ & 0,78 & $-0,22$ & 0,78 & $-0,34$ \\
\hline $\mathbf{1 3}$ & 0,7 & $-0,27$ & 0,77 & $-0,13$ \\
\hline $\mathbf{1 5}$ & 0,28 & $-0,46$ & 0,36 & 0,47 \\
\hline
\end{tabular}

\section{Supraharmonic Emission}

In [9] the terms primary and secondary emission was introduced. They are defined as:

$\checkmark \quad$ Primary emission; the part of the current that is driven by the internal emission of the device itself

$\checkmark$ Secondary emission; the part of the current that is driven by the internal emission from other devices.

The emission measured at the terminal of the PV-inverters are a combination if the two above-mentioned types. The main contribution to supraharmonic emission from the $\mathrm{PV}$-installation is primary emission due to residues from the switching in the converter.

Measurements at the $20 \mathrm{~kW}$ plant (Sweden 2) reveals that two individual components in the supraharmonic range are present in the current, $3.8 \mathrm{kHz}$ and $4.85 \mathrm{kHz}$.

An example of secondary emission is at $4.85 \mathrm{kHz}$. The $4.85 \mathrm{kHz}$ component has a peak value of $0.12 \mathrm{~A}$, and shows low correlation with the PV-production. The high emission occurs only when production is low. In this case, the high emission at this frequency occurs in the early mornings and during the night.

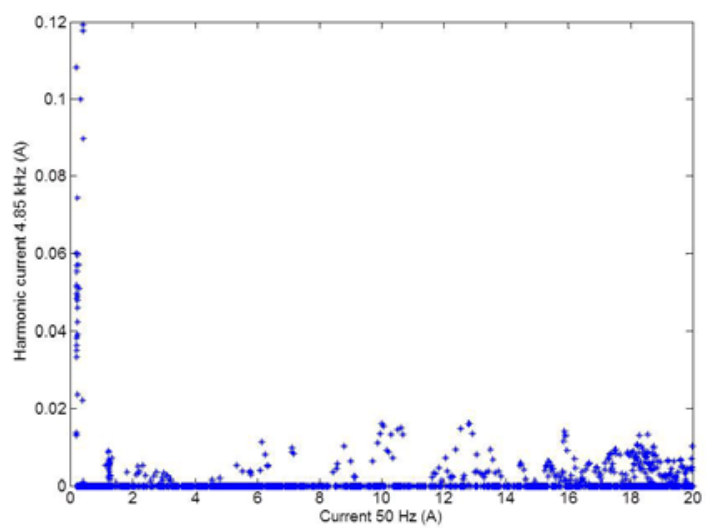

Figure 7 Amplitude of the $4.85 \mathrm{kHz}$ component for different magnitudes of the $50 \mathrm{~Hz}$ current measured at the terminal of the PV-inverter
This component is due to power-line communication used by the network operator for automated meter reading and appears during instances when data from the meters are pulled. This indicates that there are some interaction between the inverter and other equipment connected nearby [10].

An example of primary emission is visible at $3.8 \mathrm{kHz}$, The $3.8 \mathrm{kHz}$ is most likely a residue from the switching since it is always present during production and reaches zero for times with no production. The amplitude of the $3.8 \mathrm{kHz}$ component does not increase with increasing production as can be seen in Figure 5 but remains somewhat constant with a peak amplitude around $0.14 \mathrm{~A}$ during times of production.

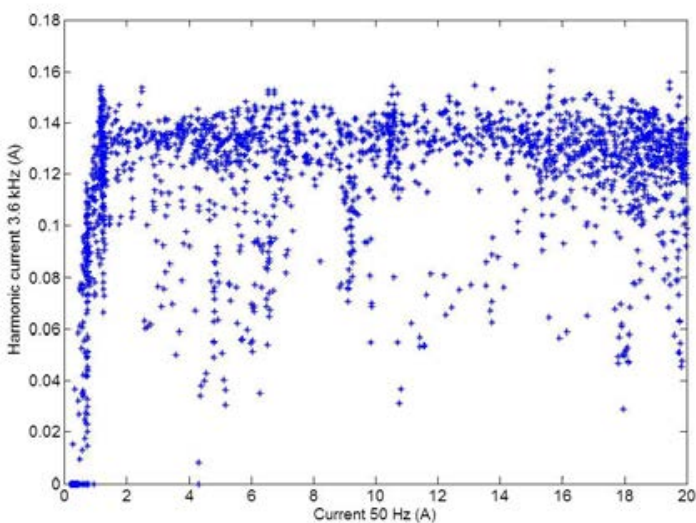

Figure 8 Amplitude of the $3.8 \mathrm{kHz}$ component for different magnitudes of the $50 \mathrm{~Hz}$ current measured at the terminal of the PV-inverter

The strongest supraharmonic component originating from the single phase $2.5 \mathrm{~kW}$ installation is at $16 \mathrm{kHz}$. This is another example of primary emission. When the solar panel is not producing any power, there is no $16-\mathrm{kHz}$ component present in the installation. In Figure 7 this component is shown for different magnitudes of current when the inverter is connected as the only device inside an installation. The amplitude of the $16 \mathrm{kHz}$ component show very little variation during production but drops to a value close to zero during times with no production.

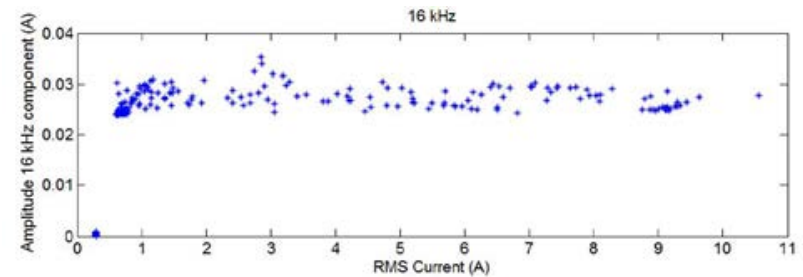

Figure 9 magnitude of the $16 \mathrm{kHz}$ component shown for different magnitudes of RMS current measured at the terminal of the PV-inverter.

As part of an experiment after secondary and primary emission a PV inverter was connected inside an installation with other common domestic equipment. The current was measured at the terminals of the inverter while other equipment was connected and disconnected to the same phase. In Figure 8 the result is shown as a spectrogram (upper left side) and frequency domain spectrum (lower left side). The spectrogram (upper right 
side) and spectrum (lower right side) from a measurement of the same inverter connected as the only device inside an installation is shown as a comparison. The current at fundamental frequency is about the same for the two measurements, 9.15 A and 9.29 A.
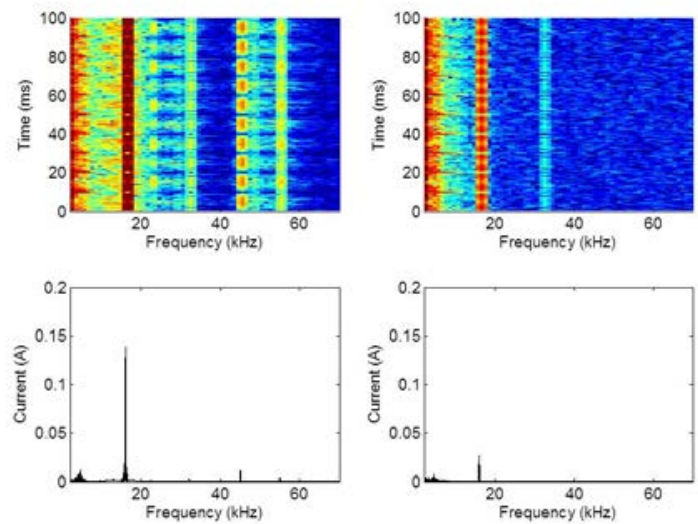

Figure 10 spectrogram (upper left side) and DFT spectra (lower left side) when other equipment is connected close to the inverter and the spectrogram (upper right side) and DFT spectra (lower right side) when the inverter is the only equipment inside the installation.

When the inverter is connected as the only device inside an installation (right hand side in Figure 8) the main frequency component visible is the $16 \mathrm{kHz}$ component. On the left hand side in Figure 8 it can be seen that other supraharmonic components appear, for instance at $45 \mathrm{kHz}$. This component is not produced by the inverter but by one of the devices connected nearby. Two things can be concluded from Figure 8;

$\checkmark \quad$ the emission at the switching frequency of $16 \mathrm{kHz}$ can increase or decrease in magnitude when other equipment is connected or disconnected

$\checkmark$ Frequency components originating from other devices are visible at the terminal of the inverter in the form of secondary emission.

\section{Conclusions}

Measurements show that the harmonic emission from a PV-installation at low-order odd harmonics is low. The emission is zero or close to zero during periods of zero production, most likely because the inverter is switched off.

Another conclusion from the measurements is that the emission spectrum up to $2 \mathrm{kHz}$ is different for the different installations. Multiple installations, from different manufacturers, connected to the same grid will thus likely have less impact than a single large installation.

Different installations and different frequencies for the same installation show different relations between emission and active-power production. Some harmonics, at some locations are strongly correlated with the produced power, whereas others are independent of the produced power.
At higher frequencies (2-150 kHz, supraharmonics) there are no standard limits to compare with, so it is difficult to class emission in this frequency range at small or low. It is shown that PV installations emit components in this frequency range.

PV installations are also shown to absorb supraharmonics present on the grid and originating from other sources like power-line communication signals and emission from other sources.

The emission from one installation might be small, but the joined emission from many installations in a domestic area may potentially be a concern. Amplification of emission due to resonances is another reason for concern. All this calls for further studies.

\section{References}

[1] M. H. J. Bollen and I. Y. H. Gu, Signal Processing of Power Quality Disturbances. Hoboken, N.J.: Wiley, 2006.

[2] R. Dugan, M. McGranaghan, S. Santosa and H. Beaty, Electric Power Systems Quality. New York: McGraw-Hill, 2012.

[3] A. Sumper and A. Baggini, Electrical Energy Efficiency: Technologies and Applications. Wiley. com, 2012.

[4] M. H. J. Bollen, P. F. Ribeiro, E. O. A. Larsson and C. M. Lundmark, "Limits for voltage distortion in the frequency range 2 to 9 kHz," IEEE Trans. Power Del., vol. 23, pp. 1481-1487, JUL, 2008.

[5] M. Klatt, J. Meyer, P. Schegner, A. Koch, J. Myrzik, C. Körner, T. Darda and G. Eberl, "Emission levels above 2 kHz laboratory results and survey measurements in public low voltage grids," in Proceedings of the 22nd International Conference and Exhibition on Electricity Distribution, Stockholm, Sweden, 2013, .

[6] A. Larsson, "On High-frequency Distortion in Low-voltage Power Systems," Doctoral Thesis, Luleå University of technology 2011.

[7] S. Rönnberg, "Power line communication and customer equipment," Licentiate Thesis, Luleå University of technology 2011.

[8] A. McEachern, "Electric Power Definitions: a Debate".

[9] Rönnberg,Sarah, Larsson, Anders, Bollen Math, Schanen Jean-Luc, " A simple model for interactions between equipment at a frequency of some tens of $\mathrm{kHz}$," in Proceedings of CIRED 21st International Conference on Electricity Distribution, Frankfurt, Germany, 2011, .

[10] S. K. Ronnberg, M. H. J. Bollen and M. Wahlberg, "Interaction Between Narrowband Power-Line Communication and End-User Equipment," Power Delivery, IEEE Transactions On, vol. 26, pp. 2034-2039, 2011. 